\title{
Determinants of utilization of a no-cost HIV transition clinic: a cross-sectional study of young adults living with HIVIAIDS
}

This article was published in the following Dove Press journal:

Adolescent Health, Medicine and Therapeutics

29 May 2014

Number of times this article has been viewed

\author{
Agnes Nyabigambo ${ }^{1,2, *}$ \\ Joshua Kanaabi Muliira ${ }^{3, *}$ \\ Lynn Atuyambe ${ }^{1, *}$ \\ Harriet M Babikako',* \\ Andrew Kambugu ${ }^{2, *}$ \\ Christopher Ndoleriire ${ }^{4, *}$ \\ 'School of Public Health, ${ }^{2}$ Infectious \\ Diseases Institute, College of Health \\ Sciences, Makerere University, \\ Kampala, Uganda; ${ }^{3}$ College of Nursing, \\ Sultan Qaboos University, Al Khod, \\ Muscat, Oman; ${ }^{4}$ Department of ENT, \\ College of Health Sciences, Makerere \\ University, Kampala, Uganda \\ *These authors contributed equally to \\ this work
}

Correspondence: Agnes Nyabigambo School of Public Health, College of Health Sciences, Makerere University, PO Box 7072, Kampala, Uganda

Tel $+256774 \quad 135496$

Fax +25631230729 |

Email agagnesgn95@gmail.com

\begin{abstract}
There is minimal research that has been conducted among young adults to understand the determinants of the utilization of human immunodeficiency virus (HIV) health services in this population. The purpose of this study was to explore the levels and determinants of HIV transition clinic (HTC) services utilization by young adults living with HIV/acquired immunodeficiency syndrome (YALHA). The study used a cross-sectional design and quantitative methods to collect data from a sample of 379 YALHA between the ages of 15-24 years who were registered clients of an HTC in Uganda. During data analysis, utilization was categorized into two levels: regular (kept all appointment visits) and irregular (missed one or more appointment visits) utilization. Univariable, bivariable, and multivariable logistic regression analyses were used to examine the determinants associated with HTC utilization. The HTC services that were most utilized by the YALHA were those based at the clinic and provided by professional health care providers and these were: clinical examination (96\%); laboratory services $(87.1 \%)$; and counseling $(69.7 \%)$. The services that were least utilized were home visiting $(5.8 \%)$ and peer support services (19.8\%). Of the 379 YALHA, only $32.4 \%$ regularly utilized the HTC. Multivariable analysis showed that the main determinants of HTC utilization were CD4 count category of $\geq 251 / \mu \mathrm{L}$ (adjusted odds ratio $[\mathrm{AOR}]=0.58,95 \%$ confidence interval $[\mathrm{CI}]=0.36-0.95$ ); not being on antiretroviral therapy $(\mathrm{AOR}=0.27,95 \% \mathrm{CI}=0.15-0.47)$; and not receiving counseling services $(A O R=0.47,95 \% \mathrm{CI}=0.27-0.83)$. Regular utilization of the HTC by YALHA was low and utilization seems to be influenced by HIV infection stage and HIV counseling services, but not sociodemographic factors or community factors.
\end{abstract}

Keywords: transition clinic, HIV/AIDS, young adults, service utilization, Uganda

\section{Introduction}

Young adults between the ages of 15 to 24 years are at an increased risk for human immunodeficiency virus (HIV) infection, mainly because this stage of life is characterized by experimentation and risky sexual behavior. ${ }^{1}$ The period of young adulthood is also characterized by an evolving sense of identity, sexual development, and initial experimentation with sexual activity. ${ }^{2}$ The initial experimentation with sexual activity plays a significant role in shaping the identities that emerge, but also exposes young adults to various health problems. ${ }^{2}$ It is well documented that young adults have high rates of risky sexual behaviors and associated sexually transmitted infections. ${ }^{3-5}$ One of the sexually transmitted infections that is common among young adults in most countries is HIV.

Globally, the prevalence of HIV in the age group of 15 to 49 years is estimated at $0.8 \%$, but the incidence of this disease remains highest among 15-24 year olds, 
with approximately $40 \%$ of HIV horizontal transmission occurring within this age group. ${ }^{6}$ The percentage of young adults (15-24 years) living with acquired immunodeficiency syndrome (AIDS) worldwide and in sub-Sharan Africa is estimated at $42 \%$ and $80 \%$ (4 million), respectively. ${ }^{7}$ In Uganda, the prevalence of HIV is estimated at $7.3 \%$, and $4 \%$ of the young adults (15-24 years) are living with HIV. ${ }^{8}$ The majority (64.6\%) of Ugandan young adults acquire the HIV infection through sexual intercourse with an HIV infected person. ${ }^{9}$ The majority of HIV-infected young adults are asymptomatic and are unlikely to become aware of their HIV infection until they become symptomatic. ${ }^{10}$

The World Health Organization defines young adulthood as the period in one's life between the age of 15 to 24 years. ${ }^{11}$ The number of YALHA is increasing partly because of the availability of antiretroviral therapy (ART) and other HIV/AIDS care services, which have made it possible for those infected at birth or in their childhood years to live up to young adulthood and adulthood. And when a young adult learns that they are infected with HIV, they face a big challenge, especially in regard to how to change one's sexual behavior. ${ }^{5}$ Many times, the YALHA and their caregivers are also not sure about where to seek HIV care or help for their unique developmental and health needs. This is the main reason why transitioning is necessary to help YALHA to bridge the gap between pediatric care and adult care. ${ }^{11}$ Transitioning is a purposeful and planned movement of YALHA from child-centered care to adult oriented HIV health care systems. The goal of HIV transitioning is to maximize lifelong function by providing high quality and developmentally appropriate HIV health care services. This opportunity aids the YALHA to continue with uninterrupted HIV care as they the individual move from young adulthood to adulthood. ${ }^{12}$ The concept of transitioning is recognized worldwide and has led to establishment of transition clinics for chronic diseases such as endocrinopathies and diabetes. ${ }^{13}$

HIV transition clinics (HTC) for YALHA have several benefits and the most commonly reported include: decreasing perceived HIV-related stigma, ${ }^{14}$ enhancing the use of HIV care services, enhancing the patient's health and other life outcomes. ${ }^{15}$ Utilization of HTC services has specifically been associated with improvements in clinical parameters such as CD4 count and viral load. ${ }^{16}$ On the other side, irregular utilization has been associated with interruption of antiretroviral therapy (ART), non-adherence to medication, and unpleasant experiences during visits to the HTC. ${ }^{17}$ ART interruptions and low adherence are important predictors of drug resistance and can lead to more complex problems such as virological and clinical failure. ${ }^{18}$ The above background highlights the importance of understanding the determinants of HTC services utilization by YALHA because such information can provide new insights into how to prevent some of negative outcomes of HIV care such as ART non-adherence and others in this patient population. Previous studies have reported some of the determinants of HTC utilization such as lack of communication and lack of developmental readiness. ${ }^{2}$ Previous studies have reported lack of communication and developmental readiness as some of the determinants of HTC utilization. ${ }^{2}$ However most of these studies were not conducted in Sub-Saharan Africa where the majority of the YALHA live. The purpose of this study was to explore the level HTC utilization and determinants of utilization of a no-cost HTC by YALHA living in Uganda (a country in Sub-Saharan Africa).

\section{Methods \\ Study design}

A cross-sectional design was used to collect data from YALHA in the age group of 15-24 years who were registered clients at an HTC in Uganda. The study was conducted between March and June 2012.

\section{Study setting}

The HTC used as the setting for this study is part of the Infectious Diseases Institute (IDI) located at Mulago Hospital in Kampala, Uganda's capital city. The services provided by all the IDI clinics (including the HTC) are offered at no cost to all enrolled clients. The IDI is funded by different government, non-government, and international organizations. ${ }^{20}$ The HTC at IDI was chosen as the study setting because it has the largest registered number of YALHA in the country and they come from both rural and urban areas.

The HTC was established in 2008 as a model clinic to provide free HIV/AIDS care (prevention, counseling, treatment, health education, and other services) and had a total of 770 registered YALHA by the time of the study. The HTC runs every Wednesday and each YALHA has a scheduled clinic visit every month. YALHA are recruited into the HTC using three strategies: referrals from the adult HIV/AIDS clinic; walk-in clients; and referrals from the pediatric infectious diseases clinic. The HTC was specifically started to address the unique challenges faced by adolescents and YALHA which were not being met in the pediatric or the adult clinics. The services used to meet the needs of YALHA include: providing clinical care related to HIV/AIDS; prevention 
of mother-to-child transmission services; family planning services; treatment for sexually transmitted infections; and HIV prevention, testing, and counseling services. The clinical care services include aspects such as psychosocial support, YALHA-specific counseling, health assessment, clinical laboratory monitoring, ART, and treatment of opportunistic infections. The other services provided at the HTC include peer support programs, skills building programs, home visits and care, and community outreach services through drama. The majority of YALHA drop out of school early because of social problems and chronic recurrent ill-health. The skills building programs helps the YALHA get trained and attain skills such as entrepreneurship and drama to help them find some form of employment or income.

\section{Study procedures}

After the study was approved by the Uganda National Council of Science and Technology and the Scientific Review Committee of the IDI, preparations for data collection were initiated. A list of YALHA registered at the HTC was obtained and used as a sampling frame. The list contained the YALHA's clinic identification number and contact telephone number. In order to attain the required sample for this study, the systematic sampling technique was used. The first participant was selected randomly from the clinic list and then contacted by telephone to communicate the invitation to participate in the study. After identifying the starting point, subsequent participants were selected using systematic sampling (sampling interval $=2$ ). In cases where the selected YALHA did not meet the inclusion criteria, the next telephone number was considered. In order to be included in the study the YALHA had to be: a registered client receiving care from the HTC; in the age range of 15-24 years; willing to provide informed consent; and in a general health condition that allows one to participate in the study (Karnofsky score of above $80 \%$ ). ${ }^{21}$ Study excluded young adults who were eligible to participate in the study but declined to the consent. Patients who were too ill to participate in the study were excluded.

The sample size needed to detect a reasonable proportion of levels of utilization of the HTC by YALHA was determined using Kish's Lisle formula for cross-sectional survey studies. ${ }^{22}$ Using benchmarks from previous reports from Uganda that showed a level of utilization of HIV-related services (prevention of mother-to-child transmission) by YALHA of $66.8 \%,{ }^{23}$ and a standard critical value for $95 \%$ confidence (1.96); the percentage of YALHA was estimated to be $32.2 \%$ and the sample needed to detect determinants of HTC utilization as 341 participants. The required sample size was adjusted upwards to 379 after factoring in a nonresponse rate of $10 \%$. Figure 1 shows a summary of the steps used to generate the sample for the study.

The eligible YALHA were invited to attend the data collection interviews conducted at a facility in the vicinity, but out of the limits of the HTC. The questionnaire was

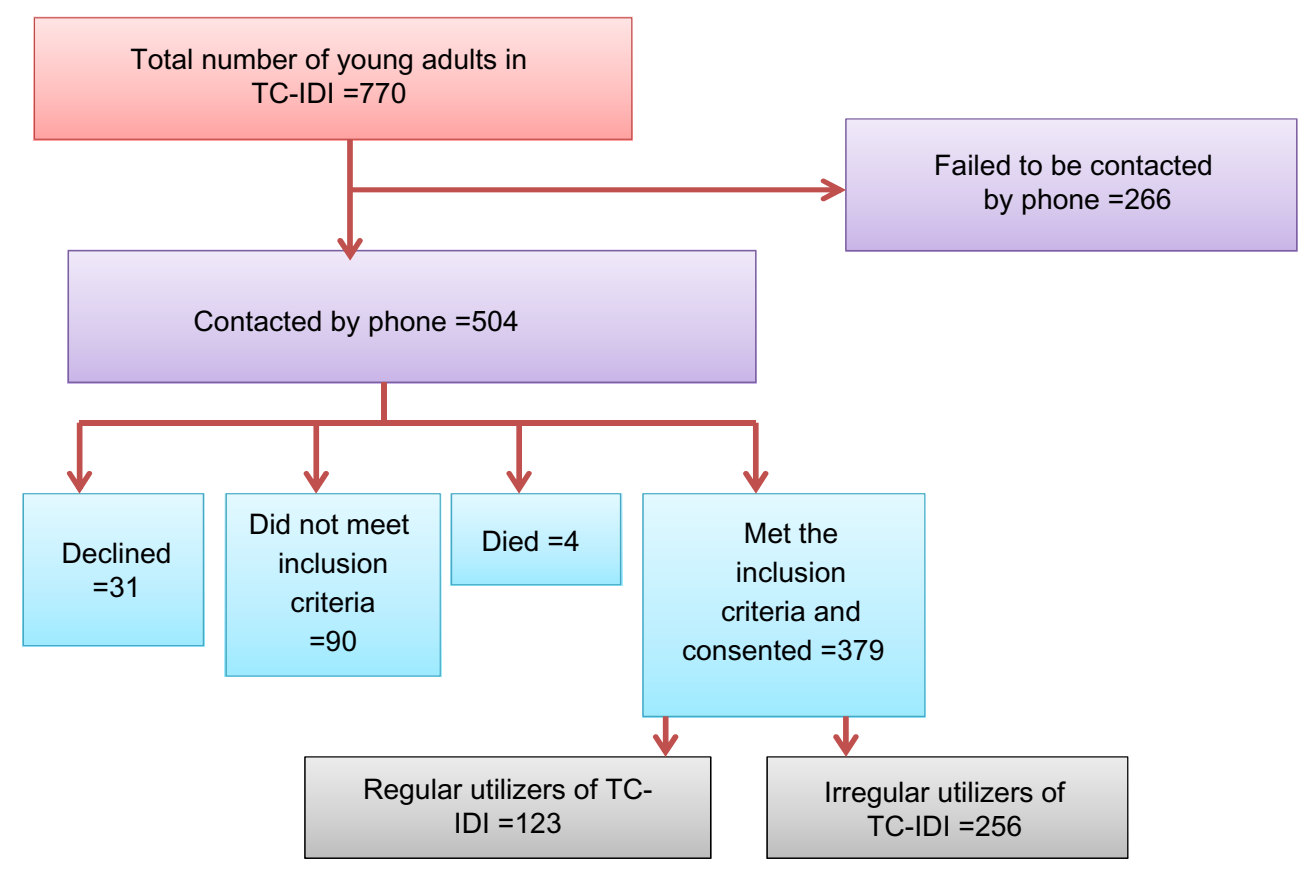

Figure I Flow diagram showing recruitment of study participants.

Abbreviations: IDI, Infectious Diseases Institute; TC-IDI, Transition Clinic at Infectious Diseases Institute. 
administered by a trained interviewer. The study purpose, and procedures were explained to the study participants. Written informed consent was obtained from study participants who were either emancipated minors (living alone or already parents) or 18 years and above. The counselor contacted the emancipated minors, invited them and determined their willingness to participate in the study. In addition, the counselor explained to them over the telephone and before the time of the data collection interview, the study purpose, procedures, benefits, and risks associated with the study. If the emancipated minor consented to participate in the study, the counselor countersigned the consent form to confirm that the necessary information was provided, was understood, and the participant was in good general condition to participate in the study. The participants who were below the age of 18 years and not emancipated minors were required to provide written informed consent only after their primary caregiver or guardian provided informed permission (assent) allowing them to participate in the study.

Each participant was interviewed once for data collection and the process (consent and data collection interview) took, on average, 50 minutes for each participant. The face-toface data collection interviews were conducted by trained research assistants using a structured and coded interview questionnaire. Participants who were found to have needs related to health care, medication refills, and support services were appropriately advised to seek the services of the HTC and other health facilities. After the data collection interviews, a review of each participant's medical records kept at the HTC was conducted to validate the participant's self-reported level of HTC utilization and CD4 counts. The documents reviewed (electronic and hardcopy medical records) helped with the verification of self-reported CD4 counts, level of utilization, and provided data about monthly scheduled appointments, and services utilized during each visit (clinical examination, laboratory services, counseling, home visits, and peer support).

\section{Study instrument and variables}

A precoded semistructured questionnaire was used to collect data during the face-to-face interviews. The questionnaire was comprised of five sections (demographic characteristics, clinical characteristics, health care delivery determinants, community determinants, and attendance of HTC appointments and services). The questionnaire was developed and written in English and translated into Luganda (local language) by an experienced translator and back-translated by a different linguistic expert to ensure consistency. Both the English and Luganda version of the questionnaire were pretested among 30 young adults at a center providing reproductive health and other health care services. The sections of the questionnaire represented the main variables measured in this study, which were: HTC utilization; YALHA predisposing determinants; health service delivery determinants; and community determinants.

HTC utilization was the main outcome variable. The level of HTC utilization was defined as the percentage of scheduled appointments the patient was able to meet by coming to the clinic in a period of six months prior to the study. The period of 6 months was adopted because follow-up studies have already shown that early loss to follow-up in HIV care programs tend to occur within this time frame in low income countries. ${ }^{24}$ The personal determinants of HTC utilization considered were demographic and clinical characteristics, mode of HIV transmission/acquisition, WHO HIV clinical stage, access to other sources of HIV/AIDS care, and ART status. The health service delivery determinants considered included waiting time at the clinic (the time taken from arrival at the HTC to the time one is seen by the doctor), rating of staff conduct, receiving health education during scheduled appointments, and freedom to express one's concerns about the HTC and the services received at the HTC. The community determinants considered were perceived discrimination due to HIV status, self-disclosure of HIV status to others, and having support from family members.

\section{Statistical analysis}

Each questionnaire was checked for completeness before the participant left the interview room and the data about HTC services utilization, CD4 counts, and ART were verified by checking medical records by at least two research team members. Statistical analyses were done using STATA SE software version 10 (StataCorp LP, College Station, TX, USA). Descriptive statistics and univariable analysis were used to describe the sample, HTC utilization, and factors associated with HTC utilization (demographic, clinical, health service, and community factors). Preliminary analysis showed that the outcome variable (HTC utilization) was not normally distributed (skewness $=-0.420$ and kurtosis $=1.966$ ). Therefore, HTC utilization was categorized into a binary outcome (regular and irregular HTC utilization). This is consistent with HIV/AIDS care, because HIV infection differs from other diseases in that if someone is receiving HIV/AIDS care, they have to utilize or receive all (100\%) of the recommended or prescribed services and care in order to attain optimal health outcomes. ${ }^{17}$ 
Regular HTC utilization was defined as a situation where, in the last 6 months, the YALHA had consistently kept all the scheduled clinic appointments (100\% utilization). On the other hand, irregular HTC utilization was defined as a situation where, in the last 6 months, the YALHA missed one or more of their scheduled clinic appointments $(<100 \%$ utilization). Chi-square tests were used for binary variables, chi-square trend tests for categorical variables with more than two groups, and $t$-tests for the continuous variables. Since the outcome variable was binary, simple and multiple logistic regression models were used to assess bivariable and multivariable associations with HTC utilization. This was achieved using a simple logistic regression model $\left(\log [\mathrm{p} / 1-\mathrm{p}]=\alpha+\beta_{1} \mathrm{X}_{1}[\log (\mathrm{p} / 1-\mathrm{p})]=\right.$ logit transformation [log odds], $\alpha=$ constant, $\beta 1=$ coefficient and $X_{1}=$ predictor variable). Variables found to be significantly associated with HTC utilization ( $P \leq 0.05$ in bivariable analyses) and those deemed to be important predictors of HTC utilization were selected for inclusion in the multivariable logistic regression models.

The associations between HTC utilization and the predictor variables were estimated using odds ratios (ORs) $(P \leq 0.05$ and $95 \%$ confidence intervals $[95 \% \mathrm{CI}])$. Adjusted OR [AOR] logistic regression using logical model building $(P=0.05)$ was carried out. Using HTC utilization (outcome variable) and CD4 counts (main exposure variable), logical model building was done by looking at how ORs and the loglikelihood of the main exposure changed as other variables were added in the model. Confounding was checked for by observing whether variables included in the model caused a change in the OR of the main exposure by at least $10 \%$ and whether a variable that was insignificant at the bivariable stage became significant at the multivariable level. The Pearson goodness-of-fit test was used to assess the final constructed logistic model.

\section{Results}

\section{Demographic and clinical characteristics of YALHA attending the HTC}

As shown in Table 1, the 379 YALHA included in the study were mostly: female ( $82 \%$ ); in the age range of 20 to 24 years (89\%); living in urban areas (64.9\%); unemployed (57.8\%); and acquired the HIV infection through sexual intercourse (64.9\%). The sample mean age was $22.5 \pm 2.0$ years, but a large number were already married (48.6\%) and had low levels of education (37.5\% primary school or less education and $46.4 \%$ secondary school level education). The majority of the participants were already on ART (61\%) and reported
Table I Demographic and clinical characteristics of YALHA attending the HTC

\begin{tabular}{|c|c|c|}
\hline Characteristic & Category & $\begin{array}{l}\text { Frequency } \\
(\mathrm{N}=379)\end{array}$ \\
\hline \multirow[t]{2}{*}{ Sex } & Male & $68(17.9 \%)$ \\
\hline & Femae & $311(82.1 \%)$ \\
\hline Age in years & $15-19$ years & $4 \mathrm{I}(10.8 \%)$ \\
\hline$($ mean $=22.5, S D=2.0)$ & $20-24$ years & $338(89.2 \%)$ \\
\hline Highest level of education & Primary school or below & $142(37.5 \%)$ \\
\hline \multirow[t]{2}{*}{ attained } & Secondary school & $176(46.4 \%)$ \\
\hline & Tertiary/university level & $61(16.1 \%)$ \\
\hline \multirow[t]{4}{*}{ Religion } & Catholic & 134 (35.4\%) \\
\hline & Protestant & $102(26.9 \%)$ \\
\hline & Moslem & $63(16.6 \%)$ \\
\hline & Pentecostal & $80(21.1 \%)$ \\
\hline \multirow[t]{2}{*}{ Employment status } & Employed & $160(42.2 \%)$ \\
\hline & Unemployed & $219(57.8 \%)$ \\
\hline \multirow[t]{2}{*}{ Location of residence } & Urban & $245(64.6 \%)$ \\
\hline & Rural & $134(35.4 \%)$ \\
\hline \multirow[t]{2}{*}{ Marital Status } & Married & I $84(48.6 \%)$ \\
\hline & Not married & $195(51.4 \%)$ \\
\hline Route through which HIV & I do not know & $64(16.9 \%)$ \\
\hline \multirow[t]{2}{*}{ was acquired } & МTCT & $69(18.2 \%)$ \\
\hline & Sexual intercourse & $246(64.9 \%)$ \\
\hline Ever accessed HIV/AIDs & Yes & $72(19.0 \%)$ \\
\hline care elsewhere & No & $307(81.0 \%)$ \\
\hline Currently on ART & Yes & $231(61.0 \%)$ \\
\hline (Antiretroviral therapy) & No & 148 (39.0\%) \\
\hline Last CD4 counts $(/ \mu \mathrm{L})$ & $\leq 250$ & $91(24.0 \%)$ \\
\hline$($ mean $=402.3 ; S D=293.3)$ & $\geq 25$ I & $288(76.0 \%)$ \\
\hline Word Health Organization & I & $93(24.5 \%)$ \\
\hline \multirow[t]{3}{*}{ (WHO) HIV clinical stage } & II & $132(34.8 \%)$ \\
\hline & III & $90(23.8 \%)$ \\
\hline & IV & 64 (16.9\%) \\
\hline
\end{tabular}

Abbreviations: AIDS, acquired immunodeficiency syndrome; ART, antiretroviral therapy; HIV, human immunodeficiency virus; HTC, HIV transition clinic; MTCT, mother-to-child transmission; SD, standard deviation; YALHA, young adults living with HIVIAIDS.

that the HTC was the only place where they were receiving HIV/AIDS care (81\%). The clinical records showed that more than half of the participants had a CD4 count $\geq 251 / \mu \mathrm{L}$ $(76 \%)$ and were distributed across the four WHO stages of HIV/AIDS as shown in Table 1.

\section{HTC utilization by YALHA}

Only one-third $(32.4 \%)$ of the 379 YALHA were regular utilizers of the HTC. The majority of the YALHA (67.6\%) utilized the HTC irregularly. The results presented in Figure 2 show that the HTC services that were most utilized by the YALHA were those based at the clinic and provided by professional health care providers. The most utilized services were clinical examination (96\%), laboratory services (87\%), and counseling $(70 \%)$. The services that were least utilized were those that were provided in the community such as 


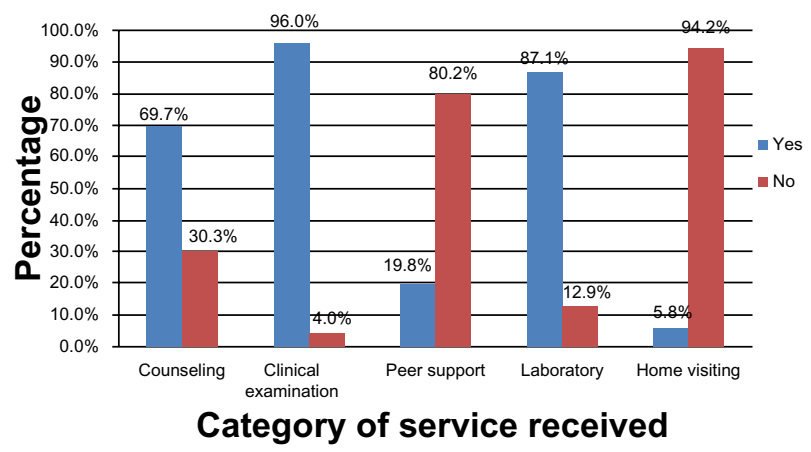

Figure 2 Graph showing HTC services utilized by YALHA in the 6 months prior to the study.

Abbreviations: AIDS, acquired immunodeficiency syndrome; HIV, human immunodeficiency virus; HTC, HIV transition clinic;YALHA, young adults living with HIVIAIDS.

home visiting $(6 \%)$ or those led by a lay person such as peer support services $(20 \%)$.

\section{Relationships between demographic and clinical characteristics with HTC utilization}

The results presented in Table 2 show significant relationships between HTC utilization and factors such as: age group of the participant $(20-24$ years $), \chi^{2}(1, n=379)=4.04, P=0.044$; residing in a rural location, $\chi^{2}(1, \mathrm{n}=379)=5.83, P=0.016$; acquiring HIV through sexual intercourse, $\chi^{2}(2, \mathrm{n}=379)=5.99, P=0.050$; not being on ART, $\chi^{2}(1, \mathrm{n}=379)=34.27, P=0.000$; and having last CD4 counts $\geq 251 / \mu \mathrm{L}, \chi^{2}(1, \mathrm{n}=379)=15.78, P=0.000$. Paired $t$-test analysis revealed that the difference in mean age of regular utilizers ( mean $=22.0 \pm 2.2$ years) and irregular utilizers (mean $=23.0 \pm 1.8$ years) was highly statistically significant, $t(379)=-4.62, P=0.000$. The difference in mean CD4 counts $/ \mu \mathrm{L}$ of regular utilizers $($ mean $=324.0 \pm 293.2 / \mu \mathrm{L})$ and irregular utilizers (mean $=440.0 \pm 286.3 / \mu \mathrm{L}$ ) was also highly statistically significant, $t(379)=-3.66, P=0.003$. Simple logistic regression analysis showed that YALHA residing in rural locations were 1.72 times more likely to be regular HTC utilizers compared to those residing in urban areas (crude OR: $1.72,95 \%$ CI: 1.11-2.68). The YALHA in the age group of 20-24 years were $49 \%$ less likely to be regular HTC utilizers compared to those in the age group of 15-19 years (crude OR: 0.51, 95\% CI: 0.27-0.99). Participants who were not taking ART were 78\% less likely to be regular HTC utilizers compared to those on ART (crude OR: 0.22, 95\% CI: $0.13-0.38$ ). Having a CD4 count $\geq 251 / \mu \mathrm{L}$ was associated with a $60 \%$ less likelihood of being a regular HTC utilizer compared to having a CD4 count $\leq 250 / \mu \mathrm{L}$. The WHO HIV clinical stages III and IV were significantly associated with
HTC utilization. Participants in the category of WHO clinical stages III were 1.94 times more likely to be regular HTC utilizers compared to those in stage I (crude OR:1.94, 95\% CI:1.03-3.65). On the other hand, participants in the category of WHO HIV clinical stage IV were 2.22 times more likely to be regular utilizers compared to those in stage I (crude OR: 2.22, 95\% CI: 1.12-4.40).

\section{Community determinants associated with HTC utilization}

The results presented in Table 3 show that not having a regular caregiver at home was the only community determinant that was significantly associated with HTC utilization, $\chi^{2}(1, \mathrm{n}=379)=6.07, P=0.014$. Bivariate analysis using simple logistic regression showed that YALHA who did not have a regular home caregiver were $54 \%$ less likely to be regular HTC utilizers compared to those who had a regular home caregiver (crude OR: 0.46, 95\% CI: 0.24-0.86).

\section{Health services delivery determinants associated with HTC utilization}

The health services delivery factors that were significantly associated with HTC utilization (Table 4) include: waiting time at the HTC, $\chi^{2}(2, \mathrm{n}=379)=4.59, P=0.011$; receiving counseling services, $\chi^{2}(1, \mathrm{n}=379)=10.11, P=0.001$; receiving clinical examination, $\chi^{2}(1, \mathrm{n}=379)=7.50$, $P=0.006$; and receiving laboratory-related services, $\chi^{2}(1, \mathrm{n}=379)=6.68, P=0.010$. Paired $t$-test analysis revealed no significant difference in average waiting time between regular utilizers (mean $=2.0 \pm 1.2$ hours) and irregular utilizers (mean $=2.0 \pm 1.3$ hours). Bivariate analysis using simple logistic regression showed that participants who reported waiting for more than 3 hours to get services were 1.76 times more likely to be regular HTC utilizers compared to those who waited for 1 hour or less (crude OR: 1.76, 95\% CI: 1.02-3.04). The participants who did not receive counseling services from the HTC were $56 \%$ less likely to be regular utilizers compared to those who received counseling services (crude OR: 0.44, 95\% CI: 0.26-0.74). Additionally, the participants who did not receive laboratory services were $64 \%$ less likely to be regular utilizers compared to those who received laboratory services (crude OR: 0.36, 95\% CI: $0.17-0.80)$.

\section{Determinants of HTC utilization by YALHA}

A multivariate logistic regression model was formulated with the dependent variable (HTC utilization). After HTC utilization 
Table 2 Relationships between YALHA demographic and clinical characteristics with HTC utilization

\begin{tabular}{|c|c|c|c|c|c|c|c|c|}
\hline Characteristic & Category & $\begin{array}{l}\text { Frequency } \\
(\mathrm{N}=379)\end{array}$ & $\begin{array}{l}\text { Regular utilizers } \\
\text { frequency } \\
(\mathrm{N}=123)\end{array}$ & $\begin{array}{l}\text { Irregular utilizers } \\
\text { frequency } \\
(\mathrm{N}=256)\end{array}$ & $\mathbf{X}^{2}$ & $P$ value & cOR & $95 \% \mathrm{Cl}$ \\
\hline \multirow[t]{2}{*}{ Sex } & Male & 68 (I7.9\%) & $22(17.9 \%)$ & $46(18.0 \%)$ & 0.00 & 0.984 & 1.00 & \\
\hline & Female & 311 (82.1\%) & 101 (82.1\%) & $210(82.0 \%)$ & & & 1.01 & $0.57-1.76$ \\
\hline \multirow{2}{*}{$\begin{array}{l}\text { Location of } \\
\text { residence }\end{array}$} & Urban & 245 (64.6\%) & $69(56.1 \%)$ & 176 (68.8\%) & 5.83 & $0.016 *$ & 1.00 & \\
\hline & Rural & I 34 (35.4\%) & $54(43.9 \%)$ & $80(31.3 \%)$ & & & 1.72 & $1.11-2.68 *$ \\
\hline \multirow{2}{*}{$\begin{array}{l}\text { Age category in } \\
\text { years }\end{array}$} & $15-19$ & $4 \mathrm{I}(10.8 \%)$ & $19(15.4 \%)$ & $22(8.6 \%)$ & 4.04 & $0.044^{*}$ & 1.00 & \\
\hline & $20-24$ & 338 (89.2\%) & $104(84.6 \%)$ & 234 (9l.4\%) & & & 0.51 & $0.27-0.99 *$ \\
\hline \multirow{3}{*}{$\begin{array}{l}\text { Highest level of } \\
\text { education attained }\end{array}$} & Primary school & $142(37.5 \%)$ & $44(35.8 \%)$ & $98(38.3 \%)$ & 0.27 & 0.875 & 1.00 & \\
\hline & Secondary school & 176 (46.4\%) & $58(47.2 \%)$ & II8 (46.1\%) & & & 1.09 & $0.68-1.76$ \\
\hline & Tertiary/university & 61 (16.1\%) & $21(17.0 \%)$ & $40(15.6 \%)$ & & & 1.17 & $0.62-2.21$ \\
\hline \multirow[t]{4}{*}{ Religion } & Catholic & 134 (35.4\%) & 47 (38.2\%) & 87 (34.0\%) & 3.09 & 0.378 & 1.00 & \\
\hline & Protestant & $102(26.9 \%)$ & $26(21.1 \%)$ & 76 (29.7\%) & & & 0.63 & $0.36-1.12$ \\
\hline & Moslem & $63(16.6 \%)$ & $22(17.9 \%)$ & $4 \mathrm{I}(16.0 \%)$ & & & 0.99 & $0.53-1.86$ \\
\hline & Pentecostal & $80(121.1 \%)$ & $28(22.8 \%)$ & $52(20.3 \%)$ & & & 1.00 & $0.56-1.78$ \\
\hline \multirow[t]{2}{*}{ Employment status } & Employed & $160(42.2 \%)$ & 47 (38.2\%) & $113(44.1 \%)$ & 1.20 & 0.274 & 1.00 & \\
\hline & Unemployed & $219(57.8 \%)$ & $76(61.8 \%)$ & I 43 (55.9\%) & & & 1.28 & $0.82-1.98$ \\
\hline \multirow[t]{2}{*}{ Marital status } & Married & I 84 (48.6\%) & $62(50.4 \%)$ & $122(47.7 \%)$ & 0.25 & 0.616 & 1.00 & \\
\hline & Not married & 195 (5I.4\%) & $61(49.6 \%)$ & I 34 (52.3\%) & & & 0.90 & $0.58-1.38$ \\
\hline \multirow{3}{*}{$\begin{array}{l}\text { Route through } \\
\text { which HIV was } \\
\text { acquired }\end{array}$} & I do not know & $64(16.9 \%)$ & $19(15.5 \%)$ & 45 (I7.6\%) & 5.99 & $0.050^{*}$ & 1.00 & \\
\hline & МTCT & $69(18.2 \%)$ & $31(25.2 \%)$ & $38(14.8 \%)$ & & & 1.93 & $0.94-3.95$ \\
\hline & Sexual intercourse & 246 (64.9\%) & 73 (59.3\%) & I 73 (67.6\%) & & & 1.00 & $0.55-1.82$ \\
\hline \multirow{2}{*}{$\begin{array}{l}\text { Accessed HIV/AIDS } \\
\text { care elsewhere }\end{array}$} & Yes & $72(19.0 \%)$ & $28(22.8 \%)$ & 44 (I7.2\%) & 1.68 & 0.195 & 1.00 & \\
\hline & No & 307 (81.0\%) & 95 (77.2\%) & $212(82.8 \%)$ & & & 0.70 & $0.4 I-1.20$ \\
\hline \multirow[t]{2}{*}{ Currently on ART } & Yes & $231(61.0 \%)$ & 101 (82.1\%) & I 30 (50.8\%) & 34.27 & $0.000 * * *$ & 100 & \\
\hline & No & I 48 (39.0\%) & $22(17.9 \%)$ & $126(49.2 \%)$ & & & 0.22 & $0.13-0.38 * *$ \\
\hline \multirow{2}{*}{$\begin{array}{l}\text { Last CD4 } \\
\text { count }(/ \mu \mathrm{L})\end{array}$} & $\leq 250$ & 91 (24.0\%) & $45(36.6 \%)$ & $46(18.0 \%)$ & 15.78 & $0.000 * * *$ & 1.00 & \\
\hline & $\geq 25$ I & $288(76.0 \%)$ & 78 (63.4\%) & $210(82.0 \%)$ & & & 0.40 & $0.25-0.62 * *$ \\
\hline \multirow{4}{*}{$\begin{array}{l}\text { WHO HIV clinical } \\
\text { stage }\end{array}$} & I & 93 (24.5\%) & $23(18.7 \%)$ & 70 (27.3\%) & 7.81 & $0.050^{*}$ & 1.00 & \\
\hline & II & | 32(34.8\%) & 38 (30.9\%) & 94 (36.7\%) & & & 1.23 & $0.67-2.25$ \\
\hline & III & $90(23.8 \%)$ & 35 (28.4\%) & 55 (21.5\%) & & & 1.94 & $1.03-3.65 *$ \\
\hline & IV & 64 (16.9\%) & 27 (22.0\%) & 37 (14.5\%) & & & 2.22 & I.12-4.40* \\
\hline
\end{tabular}

Notes: $* P$-value $\leq 0.05 ; * *$-value $\leq 0.001 ; * * *$-value $=0.000$.

Abbreviations: $95 \% \mathrm{Cl}$, 95\% confidence interval; AIDS, acquired immunodeficiency syndrome; ART, antiretroviral therapy; cOR, crude odds ratio; HIV, human immunodeficiency virus; HTC, HIV transition clinic; MTCT, mother-to-child transmission; WHO, World Health Organization; YALHA, young adults living with HIV/AIDS; CD4, T-helper cells; $\left(\chi^{2}\right)$, chi-square; $N$, number; $P$-value, level of significance.

Table 3 Community determinants of HTC utilization by YALHA

\begin{tabular}{|c|c|c|c|c|c|c|c|}
\hline $\begin{array}{l}\text { Community factor } \\
\text { and response }\end{array}$ & $\begin{array}{l}\text { Frequency } \\
(\mathrm{N}=379)\end{array}$ & $\begin{array}{l}\text { Regular utilizers } \\
\text { frequency } \\
(\mathrm{N}=123)\end{array}$ & $\begin{array}{l}\text { Irregular utilizers } \\
\text { frequency }(\mathrm{N}=\mathbf{2 5 6})\end{array}$ & $\mathbf{X}^{2}$ & $P$ value & cOR & $95 \% \mathrm{Cl}$ \\
\hline \multicolumn{8}{|c|}{ Has a family member to remind about appointments } \\
\hline Yes & $238(63.0 \%)$ & 85 (70.0\%) & $153(60.0 \%)$ & & & 1.00 & \\
\hline No & $140(37.0 \%)$ & $37(30.0 \%)$ & $103(40.0 \%)$ & 3.48 & 0.062 & 0.65 & $0.4 I-I .02$ \\
\hline \multicolumn{8}{|c|}{ Feels rejected because of HIV status } \\
\hline Yes & $76(20.0 \%)$ & $27(22.0 \%)$ & 49 (19.0\%) & & & 1.00 & \\
\hline No & $303(80.0 \%)$ & $96(78.0 \%)$ & $207(81.0 \%)$ & 0.41 & 0.522 & 0.84 & $0.50-1.43$ \\
\hline \multicolumn{8}{|c|}{ Disclosed HIV status to another person who is not a HPC } \\
\hline Yes & $354(93.4 \%)$ & $112(91.1 \%)$ & $242(94.5 \%)$ & & & 1.00 & \\
\hline No & $25(6.6 \%)$ & II (8.9\%) & $14(5.5 \%)$ & 1.63 & 0.202 & 1.70 & $0.75-3.86$ \\
\hline \multicolumn{8}{|c|}{ Has a regular caregiver at home } \\
\hline Yes & 309 (8I.5\%) & $109(88.6 \%)$ & $200(78.1 \%)$ & & & 1.00 & \\
\hline No & $70(18.5 \%)$ & $14(1 \mathrm{l} .4 \%)$ & $56(21.9 \%)$ & 6.07 & $0.014 *$ & 0.46 & $0.24-0.86 *$ \\
\hline
\end{tabular}

Note: $* P$-value $\leq 0.05$.

Abbreviations: $95 \% \mathrm{Cl}, 95 \%$ confidence interval; AIDS, acquired immunodeficiency syndrome; cOR, crude odds ratio; HIV, human immunodeficiency virus; HPC, health care provider; HTC, HIV transition clinic; YALHA, young adults living with HIVIAIDS; $\left(\chi^{2}\right)$, chi-square. 
Table 4 Health services delivery factors associated with HTC utilization by YALHA

\begin{tabular}{|c|c|c|c|c|c|c|c|c|}
\hline $\begin{array}{l}\text { Health services } \\
\text { delivery determinants }\end{array}$ & Category & $\begin{array}{l}\text { Frequency } \\
(\mathrm{N}=379)\end{array}$ & $\begin{array}{l}\text { Regular utilizers } \\
\text { frequency } \\
(\mathrm{N}=123)\end{array}$ & $\begin{array}{l}\text { Irregular utilizers } \\
\text { frequency } \\
(\mathrm{N}=256)\end{array}$ & $\mathbf{X}^{2}$ & $P$ value & cOR & $95 \% \mathrm{Cl}$ \\
\hline Waiting time during clinic & $0-1$ & $139(36.7 \%)$ & $36(29.3 \%)$ & $103(40.2 \%)$ & & & 1.00 & \\
\hline \multirow[t]{2}{*}{ appointments (hours) } & $1-2$ & $135(35.6 \%)$ & 47 (38.2\%) & $88(34.4 \%)$ & & & 1.53 & $0.91-2.57$ \\
\hline & $>3$ & $105(27.7 \%)$ & 40 (32.5\%) & $65(25.4 \%)$ & 4.59 & 0.101 & 1.76 & $1.02-3.04 *$ \\
\hline Rating of the general conduct & Very good & $234(61.7 \%)$ & 77 (62.6\%) & $157(61.3 \%)$ & & & 1.00 & \\
\hline of the clinic staff & Good & $145(38.3 \%)$ & 46 (37.4\%) & $99(38.7 \%)$ & 0.06 & 0.81 & 0.95 & $0.6 I-1.48$ \\
\hline Feels free to express feelings & Yes & $148(39 \%)$ & $44(36 \%)$ & $104(40.6 \%)$ & & & 1.00 & \\
\hline about clinic & No & $231(61 \%)$ & 79 (64\%) & $152(59.4 \%)$ & 0.82 & 0.37 & 1.23 & $0.79-1.92$ \\
\hline Attends health education at & Yes & $198(52.2 \%)$ & 69 (56.1\%) & $129(50.4 \%)$ & & & 1.00 & \\
\hline the clinic & No & I8I (47.8\%) & 54 (43.9\%) & $127(49.6 \%)$ & 1.08 & 0.30 & 0.79 & $0.52-1.22$ \\
\hline \multirow[t]{2}{*}{ Utilized counseling services } & Yes & $264(69.7 \%)$ & 99 (80.5\%) & $165(64.5 \%)$ & & & 1.00 & \\
\hline & No & $115(30.3 \%)$ & 24 (19.5\%) & $91(35.5 \%)$ & 10.11 & $0.001 * *$ & 0.44 & $0.26-0.74 * *$ \\
\hline Utilized clinical examination & Yes & $364(96 \%)$ & $123(100 \%)$ & $24 I(94.1 \%)$ & & & & \\
\hline services & No & $15(4 \%)$ & $0(0 \%)$ & $15(5.9 \%)$ & 7.50 & $0.006 *$ & - & - \\
\hline Utilized peer support & Yes & $75(19.8 \%)$ & $29(23.6 \%)$ & $46(18 \%)$ & & & 1.00 & \\
\hline services offered by clinic & No & $304(80.2 \%)$ & $94(76.4 \%)$ & $210(82 \%)$ & 1.65 & 0.199 & 0.71 & $0.42-1.20$ \\
\hline \multirow{2}{*}{ Utilized laboratory services } & Yes & $330(87.1 \%)$ & 115 (93.5\%) & $215(84 \%)$ & & & 1.00 & \\
\hline & No & $49(12.9 \%)$ & $8(6.5 \%)$ & $41(16 \%)$ & 6.68 & $0.010^{*}$ & 0.36 & $0.17-0.80 * *$ \\
\hline Utilized home visiting services & Yes & $22(5.8 \%)$ & $5(4.1 \%)$ & $17(6.6 \%)$ & & & 1.00 & \\
\hline of the clinic & No & $357(94.2 \%)$ & $118(95.9 \%)$ & $239(93.4 \%)$ & I.0I & 0.315 & 1.68 & $0.60-4.66$ \\
\hline
\end{tabular}

Notes: $* P$-value $\leq 0.05 ; * * P$-value $\leq 0.00$ I.

Abbreviations: $95 \% \mathrm{Cl}, 95 \%$ confidence interval; AIDS, acquired immunodeficiency syndrome; cOR, crude odds ratio; HIV, human immunodeficiency virus; HTC, HIV transition clinic; YALHA, young adults living with HIVIAIDS; $\left(\chi^{2}\right)$, chi-square.

(regular and irregular utilization), the first independent variable to be entered in the model was CD4 count category, followed by ART status and others as shown in Table 5. The selected final model had CD4 count category, ART status, receipt of counseling services, location of residence, receipt of laboratory services, waiting time, sex, and having a regular caregiver at home. The results of the Pearson test for goodness-of-fit for the final model showed a $P$-value of 0.563 , indicating that the model is good $(P>0.05$ and chi-square value $=128.80)$. The log-likelihood $(-207.15)$ reaffirms the goodness of the model and as summarized in Table 5, the final model shows that YALHA with a CD 4 count $\geq 251 / \mu \mathrm{L}$ were $42 \%$ less likely to be regular utilizers compared to those with a CD4 count $\leq 250 / \mu \mathrm{L}$ after holding constant all of the other variables in the model (AOR: 0.58,

Table 5 Determinants of HTC utilization by YALHA

\begin{tabular}{|c|c|c|c|c|c|}
\hline Factor & Category & cOR & $95 \% \mathrm{Cl}$ & aOR & $95 \% \mathrm{Cl}$ \\
\hline \multirow[t]{2}{*}{ CD4 count category $(/ \mu \mathrm{L})$} & $\leq 250$ & 1.00 & & 1.00 & \\
\hline & $\geq 25$ I & 0.40 & $0.25-0.62 * * *$ & 0.58 & $0.36-0.95 * *$ \\
\hline \multirow[t]{2}{*}{ Currently on antiretroviral therapy } & Yes & 1.00 & & 1.00 & \\
\hline & No & 0.22 & $0.13-0.38 * * *$ & 0.27 & $0.15-0.47^{* * *}$ \\
\hline \multirow[t]{2}{*}{ Received counseling services } & Yes & 1.00 & & 1.00 & \\
\hline & No & 0.44 & $0.26-0.74 * *$ & 0.47 & $0.27-0.83^{* * *}$ \\
\hline \multirow[t]{2}{*}{ Location of place of residence } & Urban & 1.00 & & 1.00 & \\
\hline & Rural & 1.72 & $1.11-2.68 * *$ & 1.59 & $0.98-2.58$ \\
\hline \multirow[t]{2}{*}{ Received laboratory services } & Yes & 1.00 & & 1.00 & \\
\hline & No & 0.36 & $0.17-0.80 * *$ & 0.52 & $0.22-1.22$ \\
\hline HTC waiting time categories & $0-1$ & 1.00 & & 1.00 & \\
\hline \multirow[t]{2}{*}{ during visits in hours } & $1-2$ & 1.53 & $0.91-2.57$ & 1.25 & $0.7 I-2.21$ \\
\hline & $>3$ & 1.76 & $1.02-3.04 * *$ & 1.44 & $0.80-2.61$ \\
\hline Do you have a regular caregiver & Yes & 1.00 & & 1.00 & \\
\hline at home? & No & 0.46 & $0.24-0.86 * *$ & 0.67 & $0.34-1.33$ \\
\hline \multirow[t]{2}{*}{ Sex } & Male & 1.00 & & 1.00 & \\
\hline & Female & 1.01 & $0.57-1.74$ & 1.04 & $0.56-1.93$ \\
\hline
\end{tabular}

Notes: $* * P$-value $\leq 0.001 ; * * * P$-value $=0.000$; log-likelihood $=-207.10$; Pearson I-fit prob $>\chi^{2}=0.607$.

Abbreviations: $95 \% \mathrm{Cl}$, 95\% confidence interval; AIDS, acquired immunodeficiency syndrome; aOR, adjusted odds ratio; cOR, crude odds ratio; $\mathrm{HIV}$, human immunodeficiency virus; HTC, HIV transition clinic; YALHA, young adults living with HIVIAIDS. 
95\% CI: 0.36-0.95). ART status (not being on ART) was found to be a significant determinant of HTC utilization because the model shows that participants who were not yet on ART were $73 \%$ less likely to be regular utilizers compared to those on ART (AOR: 0.27, 95\% CI: 0.15-0.47). Additionally, not receiving counseling services was found to be a significant determinat of HTC utilization level. YALHA who did not receive counseling services were found to be $53 \%$ less likely to be regular utilizers compared to those who received counseling services (AOR: 0.47, 95\% CI: $0.27-0.83$ ).

\section{Discussion}

The findings of this study show that the majority of YALHA who are clients at the HTC were unemployed females in the age group of 20-24 years who acquired HIV through sexual intercourse. This description of YALHA is consistent with findings of other HIV studies in Uganda and sub-Saharan Africa, which have shown that HIV is most prevalent among women living in urban areas. ${ }^{25,26}$ Similarly, one study has shown that young adults living with HIV are sexually active and do not disclose their HIV status among their peers. ${ }^{27}$ However, it is important to note that females in general also tend to have better health-seeking behaviors and this could be one of the reasons to explain their large number in the sample for the current study. The lower levels of education and social economic status among YALHA at the HTC are not surprising because it has already been reported by other studies that this population tends to drop out of school early due to loss of parents, chronic diseases, and other social factors. ${ }^{28}$ Early school dropout subsequently leads to lack of skills and qualifications and this reduces the chances of attaining gainful employment among YALHA. ${ }^{28} \mathrm{~A}$ study conducted in South Africa among 7,665 youths also found that most YALHA were in the age group of 20-24 years (64\%), but unlike the ones in the current study, most of them lived in rural areas (53\%). ${ }^{29}$ Considering the spread of YALHA in both rural and urban areas, levels of unemployment, and lower levels of education, it is very important to ensure that there is equitable access to HIV prevention and care services delivered through appropriate outlets such as the HTC in both rural and urban areas of Sub-Saharan countries.

The other findings of this study, showing that a third of the YALHA (32.4\%) were not utilizing the HTC regularly and that the majority of regular utilizers were mainly female (82\%), highlight a very important challenge in regard to the male YALHA. Although the findings point to what is already known about female clients as being better and more committed health seekers ${ }^{30}$ and male clients as poor health seekers, ${ }^{30}$ it is important to have additional studies about the impact of gender norms, gender roles, and masculinity on HIV care-seeking behaviors among YALHA. The other findings, which revealed that the HTC services that were most utilized by the YALHA were those based at the clinic and provided by professional health care providers, while the least utilized were those which necessitated contact with the community or individuals from the community, also highlight an area that needs further exploration. The low level of utilization of services involving home care and peer support is an important finding and may be indicative of the fear YALHA have about others knowing that they are infected with HIV. The literature shows that a lack of preference for community-based or community-oriented HIV care services is mainly driven by fear of social stigma and discrimination that occurs when others in the community get to know that one has HIV at a young age. ${ }^{31}$ In young adults, HIV stigma elicits a lot of fear because it can lead to job loss and being perceived as "weak" or "unmanly," especially for males. ${ }^{31}$ The HTC clinic used for the this study did not require the YALHA to pay for any of the services, therefore the barriers that commonly prevent women from getting health care such as lack of access and control over resources were limited. However, other factors such as childcare responsibilities that restrict mobility and limit decision-making power at home need be explored because they can limit women's HTC utilization. ${ }^{31}$

The most significant determinants of HTC utilization (CD4 counts, not being on ART, and not receiving counseling services) found by the current study show that when the YALHA are feeling strong, healthy (CD4 counts $\geq 251 / \mu \mathrm{L}$ ), or without opportunistic infections, they do not feel the need to attend the HTC regularly. In addition, YALHA with CD4 counts $\geq 251 / \mu \mathrm{L}$ may not have received intensive counseling services about ART adherence because they may not have initiated this kind of treatment compared to those who have a CD4 count $\leq 250 / \mu \mathrm{L}$. This explains why not being on ART and having a CD4 count $\geq 251 / \mu \mathrm{L}$ reduces the chance of being a regular HTC utilizer. The findings about the relationship between ART status and HTC utilization, are similar to what has been reported about hard-to reach HIV-infected individuals in the city of Atlanta in USA,,${ }^{17}$ and to the results of a randomized behavioral trial that examined whether youth living with HIV receiving cell-phone support would demonstrate improved adherence and viral control in US. ${ }^{32}$ It has previously been reported that young adults receiving ART build a trusting relationship and closeness with their physician and health care team. ${ }^{33}$ However, 
a Canadian study that examined the relationship between CD4 counts and emergency services utilization reported that there was no relationship between HIV care utilization and CD4 count. ${ }^{34}$ There was an earlier study which reported findings showing that lower CD4 counts (OR 2.79 for $<200$ cells $/ \mathrm{mm}^{3}$, 95\% CI: 1.44-5.43) was associated with irregular utilization of a drug assistance program. ${ }^{35}$ This inconsistency in findings about clinical parameters and HIV care services utilization can potentially be explained by the effect of decreasing ability to make decisions to go to places where care is provided. It is possible that as the YALHA's immunity decreases, the volition to attend HTC appointments decreases, and at this point the help of someone like a caregiver at home to remind, encourage, and assist them to seek health care becomes critical. The new Ugandan guidelines which require initiation of ART in all people living with HIV with a CD4 count of $>350 / \mu \mathrm{L}$ appropriately address this trajectory. ${ }^{36}$

\section{Study limitations}

The findings of this study are limited by the lack of a standardized measure of HTC utilization. There was also no data available to estimate how long each respondent had been HIV-positive. Despite its limitations, the current study highlights key aspects about YALHA and HTC services utilization that need to be enhanced and studied further. Health care providers and managers of HTCs and other HIV care programs for YALHA need to focus on increasing access to HIV counseling in rural and urban areas, and developing innovative strategies to attract YALHA who are ART-naïve to utilize both clinic-based and communitybased HIV care services. Cohort studies and experimental studies about effective strategies that can be used to enhance HTC utilization and community-based HIV care services by YALHA will be very beneficial.

\section{Conclusion}

YALHA have low levels of regular HTC utilization, but females tend to be better service utilizers. The key determinants of HTC utilization are CD4 count, ART status, and HIV counseling. Therefore, there is need for HTC and all HIV care programs to initiate regular HIV counseling services for ART-naïve YALHA. The results of this study also inform us of the need to update the planning of HTC services and to design effective interventions to enhance utilization of clinic- and community-based HIV care services, and living positively with HIV because these interventions enhance the health outcomes of YALHA.

\section{Acknowledgments}

This work was supported by Training Health Researchers into Vocational Excellence in East Africa (THRiVE), grant number 087540 funded by the Wellcome Trust. Its contents are solely the responsibility of the authors and do not necessarily represent the official views of the supporting offices. The authors wish to recognize the help and assistance from staff and administrators of the Infectious Diseases Institute at Makerere University.

\section{Disclosure}

The authors report no conflicts of interest in this work.

\section{References}

1. Moore S, Parsons JT. A research agenda for adolescent risk-taking: where do we go from here? J Adolesc. 2000;23(4):371-376.

2. Wiener LS, Kohrt BA, Battles HB, Pao M. The HIV experience: youth identified barriers for transitioning from pediatric to adult care. J Pediatr Psychol. 2011;36(2):141-154.

3. Hein K, Dell R, Futterman D, Rotheram-Borus MJ, Shaffer N. Comparison of HIV+ and HIV- adolescents: risk factors and psychosocial determinants. Pediatrics. 1995;95(1):96-104.

4. Murphy DA, Durako SJ, Moscicki A, et al. Adolescent Medicine HIV/ AIDS Research Network. No change in health risk behaviors over time among HIV infected adolescents in care: role of psychological distress. J Adolesc Health. 2001;29(Suppl 3):57-63.

5. Naar-King S, Wright K, Parsons J, Frey M, Templin T, Ondersma S. Transtheoretical model and substance use in HIV+ youth. AIDS Care. 2006;18(7):839-845.

6. World Health Organization, UNAIDS, UNICEF. Towards Universal Access: Scaling up Priority HIV/AIDS Interventions in the Health Sector. Progress Report 2008. Geneva: World Health Organization; 2008. Available from: http://www.who.int/hiv/pub/towards_universal_access_report_2008. pdf?ua=1. Accessed January 8, 2011.

7. UNAIDS. UNAIDS WorldAIDS Day Report 2011. Geneva: UNAIDS; 2011. Available from: http://www.unaids.org/en/media/unaids/contentassets/documents/unaidspublication/2011/jc2216_worldaidsday_report_2011_en.pdf. Accessed December 2, 2011.

8. Uganda Ministry of Health. Release of Key Results of the 2011 Uganda AIDS Indicator Survey [press release]. Kampala: Uganda Ministry of Health; July 5, 2012. Available from: http://acetuganda.wordpress. com/2012/07/05/the-2011-uganda-aids-indicator-survey/. Accessed January 8, 2012.

9. Bakeera-Kitaka S, McAdam K, Kambugu A, et al. Assessing the Transitional Needs of 'Young Adult' Patients at the Infectious Diseases Institute. Journal Club Presentation. 2009.

10. Johnson RL, Martinez J, Botwinick G, et al. Introduction: what youth need - adapting HIV care models to meet the lifestyles and special needs of adolescents and young adults. $J$ Adolesc Health. 2003; 33(Suppl 2):4-9.

11. Catallozzi M, Futterman D. HIV in adolescents. Curr Infect Dis Rep. 2005;7:401-405.

12. Collis F, Finger E, Okerstrom E, Owens K. Review of Transition of Young Adults Clinics FINAL REPORT - ATTACHMENT 6: LITERATURE REVIEW. Ipsos-Eureka, Social Research Institute; 2008. Available from: http://health.vic.gov.au/subacute/literature-review.pdf. Accessed January 7, 2011.

13. Phan-Hug F, Hauschild M, Dwyer A, Pitteloud N. [Caring for patients with pediatric endocrinopathies and diabetes into adulthood: challenges of an often difficult transition]. Rev Med Suisse. 2012;8(362): 2170-2172, 2174. French. 
14. Cervia JS. Transitioning HIV-infected children to adult care. J Pediatr. 2007;150(1):e1.

15. Li R. Growing up on HAART: The experiences and needs of HIV positive adolescents in care and treatment in the Western Cape Province of South Africa. CSSR. 2009;249.

16. Johnson RL, Botwinick G, Sell RL, et al. The utilization of treatment and case management services by HIV-infected youth. JAdolesc Health. 2003;33(Suppl 2):31-38.

17. Rebolledo P, Kourbatova E, Rothenberg R, Rio C. Factors associated with utilization of HAART amongst hard-toreach HIV-infected individuals in Atlanta, Georgia. J AIDS HIV Res. 2011;3(3):63-70.

18. Oyugi JH, Byakika-Tusiime J, Ragland K, et al. Treatment interruptions predict resistance in HIV-positive individuals purchasing fixeddose combination antiretroviral therapy in Kampala, Uganda. AIDS. 2007;21(8):965-971.

19. World Health Organization. Young people: health risks and solutions. World Health Organization; 2011.Available from: www.who.int/entity/ mediacentre/factsheets/fs345/en/. Accessed on March 10, 2012.

20. Infectious Disease Institute. Annual Report 2011. Kampala: Infectious Diseases Institute, College of Health Sciences, Makerere University;2011. Available from: http://www.idi-makerere.com/index.php?option= com_docman\&task=doc_view \&gid=11\&tmpl=component $\&$ format=raw\&Itemid=58. Accessed January 27, 2014.

21. Karnofsky DA, Burchenal JH. The Clinical Evaluation of Chemotherapeutic Agents in Cancer. In: MacLeod CM, editor. Evaluation of Chemotherapeutic Agents. New York: Columbia University Press; 1949:196.

22. Kish L. Survey Sampling, Volume 105. New York: John Wiley and Sons, Inc.; 1965.

23. Birungi H, Obare F, van der Kwaak A, Namwebya JH. Maternal health care utilization among HIV-positive female adolescents in kenya. Int Perspect Sex Reprod Health. 2011;37(3):143-149.

24. Brinkhof MW, Dabis F, Myer L, et al; ART-LINC, IeDEA. Early loss of HIV-infected patients on potent antiretroviral therapy programmes in lower-income countries. Bull World Health Organ. 2008;86(7): 559-567.

25. Ayiga N. Rates and predictors of consistent condom-use by people living with HIV/AIDS on antiretroviral treatment in Uganda. $J$ Health Popul Nutr. 2012;30(3):270-280.
26. Turan JM, Hatcher AH, Medema-Wijnveen J, et al. The role of HIVrelated stigma in utilization of skilled childbirth services in rural Kenya: a prospective mixed-methods study. PLos Med. 2012;9(8): e1001295.

27. Boudreau ME, Fisher CM. Providing effective medical and case management services to HIV-infected youth preparing to transition to adult care. J Assoc Nurses AIDS Care. 2012;23(4):318-328.

28. Farid-ul-Hasnain S, Krantz G. Assessing reasons for school/college dropout among young adults and implications for awareness about STDs and HIV/AIDS: findings from a population-based study in Karachi, Pakistan. Int J Behav Med. 2011;18(2):122-130.

29. MacPhail C, Pettifor A, Moyo W, Rees H. Factors associated with HIV testing among sexually active South African youth aged 15-24 years. AIDS Care. 2009;21(4):456-467.

30. Parrott FR, Mwafulirwa C, Ngwira B, et al. Combining qualitative and quantitative evidence to determine factors leading to late presentation for antiretroviral therapy in Malawi. PLoS One. 2011;6(11):e27917.

31. World Health Organization. Gender inequalities and HIV. Gender, Women and Health, Report. 2008. Geneva: World Health Organization; 2008. Available from: http://www.who.int/gender/hiv_aids/en/. Accessed on April 9, 2012.

32. Belzer ME, Naar-King S, Olson J, et al. The Adolescent Medicine Trials Network for HIV/AIDS Interventions. The use of cell phone support for non-adherent HIV-infected youth and young adults: an initial randomized and controlled intervention trial. AIDS Behav. Epub November 24, 2013.

33. Fernet M, Richard M-E, Lévy JJ, et al. Transition to adult clinics in youth living with HIV since birth. Retrovirology. 2010;7(Suppl 1):P116.

34. Fairbairn N, Milloy MJ, Zhang R, et al. Emergency department utilization among a cohort of HIV-positive injecting drug users in a Canadian setting. J Emerg Med. 2012;43(2):236-243.

35. Godwin NC, Willig JH, Nevin CR, et al. Underutilization of the AIDS Drug Assistance Program: associated factors and policy implications. Health Serv Res. 2011;46(3):982-995.

36. Uganda Ministry of Health. The Integrated National Guidelines on Antiretroviral Therapy, Prevention of Mother to Child Transmission of HIV and Infant and Young Child Feeding. Kampala: Uganda Ministry of Health; 2011. http://www.k4health.org/toolkits/uganda-positivelivingcommunication/integrated-national-guide. Accessed on April 9, 2012.

\section{Publish your work in this journal}

Adolescent Health, Medicine and Therapeutics is an international, peer-reviewed, open access journal focusing on health, pathology, and treatment issues specific to the adolescent age group. All aspects of health maintenance, preventative measures and disease treatmen interventions are addressed within the journal and practitioners from

\section{Dovepress}

all disciplines are invited to submit their work as well as healthcare researchers and patient support groups.. The manuscript management system is completely online and includes a very quick and fair peerreview system. Visit http://www.dovepress.com/testimonials.php to read real quotes from published authors. 